\title{
Big Data Analytics and Innovation Performance with the Transformational Role of Management Accountant
}

Sabra Munir, Siti Zaleha Abdul Rasid, Muhammad Aamir, Farrukh Jamil, Ishfaq Ahmed

To Link this Article: http://dx.doi.org/10.6007/IJARBSS/v11-i11/11601

DOI:10.6007/IJARBSS/v11-i11/11601

Received: 21 September 2021, Revised: 25 October 2021, Accepted: 10 November 2021

Published Online: 17 November 2021

In-Text Citation: (Munir et al., 2021)

To Cite this Article: Munir, S., Rasid, S. Z. A., Aamir, M., Jamil, F., \& Ahmed, I. (2021). Big Data Analytics and Innovation Performance with the Transformational Role of Management Accountant. International Journal of Academic Research in Business and Social Sciences, 11(11), 1180 - 1197.

Copyright: (c) 2021 The Author(s)

Published by Human Resource Management Academic Research Society (www.hrmars.com)

This article is published under the Creative Commons Attribution (CC BY 4.0) license. Anyone may reproduce, distribute, translate and create derivative works of this article (for both commercial and non-commercial purposes), subject to full attribution to the original publication and authors. The full terms of this license may be seen

at: http://creativecommons.org/licences/by/4.0/legalcode

Vol. 11, No. 11, 2021, Pg. 1180 - 1197

Full Terms \& Conditions of access and use can be found at http://hrmars.com/index.php/pages/detail/publication-ethics 


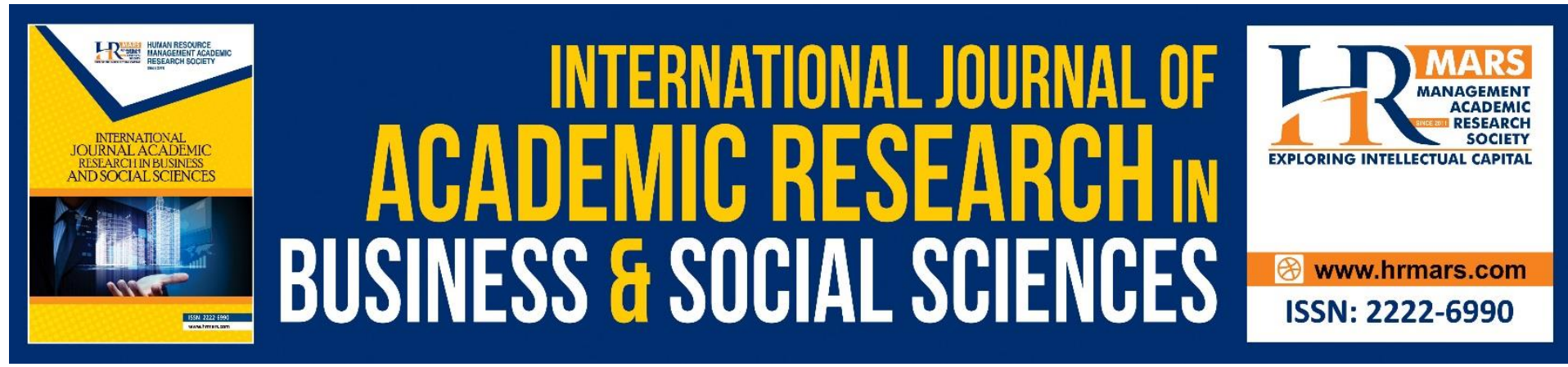

\title{
Big Data Analytics and Innovation Performance with the Transformational Role of Management Accountant
}

\author{
Sabra Munir ${ }^{1}$, Siti Zaleha Abdul Rasid², Muhammad Aamir ${ }^{3}$, \\ Farrukh Jamil ${ }^{4}$, Ishfaq Ahmed ${ }^{5}$ \\ ${ }^{1}$ Azman Hashim International Business School, University of Technology Malaysia, ${ }^{2}$ Azman \\ Hashim International Business School, University of Technology Malaysia, ${ }^{2}$ University of \\ Business and Technology, Jeddah, Saudi Arabia, ${ }^{3}$ Hailey College of Commerce, University of \\ the Punjab, Pakistan, ${ }^{4}$ Department of Management Sciences, FAST National University of \\ Computer and Emerging Sciences, Pakistan, ${ }^{5}$ Hailey College of Commerce, University of the \\ Punjab, Pakistan
}

Corresponding author Email: sabra_munir@hotmail.com

\begin{abstract}
The purpose of this paper is to contribute to the literature on the impact of Big Data Analytics Capabilities (BDAC) on the Organizational Innovation Performance (OIP) with the transformational role of Management Accountant. By carrying out a literature review, this paper provides information for researchers and scholars to explore the emerging trends and implications of the above-mentioned relationship. A literature review highlights the emerging issues from the research conducted on Organizational Innovative Performance, Big Data and the role of Management Accountant in this relationship by focusing on: role of OIP, the importance of Big Data from the technological to the managerial paradigm as well as the role a Management Accountant can play in the era of Big Data. It is expected that identifying these contributions will help establish future research directions. The paper provides a number of avenues for potential research in this emerging area of investigation. The main aim of the key research questions posed is to further the contribution of Big Data towards research on Organizational Innovative Performance. The paper outlines how the organizations which are developing their approaches for big data analytics capabilities can focus on the factors and variables which are relevant for them to develop their big data analytics capabilities so as to develop their sustainable competitive advantages. This paper investigates the effects and implications which organizations can have by using Big Data to achieve innovative performance. At the same time, it provides an original understanding of the contextual importance of investing in the big data analytics capabilities development. It also considers the role played by management accountant as a bridge between the data scientists and the business requirements in a big data environment. As a result, the current study aims to show the impact which Big Data Analytics (BDA) Capabilities have on the organizational innovation performance with organizational culture and role of management accountant as moderators. The study will use data from surveys of CFOs, CEOs or CIOs of the pharmaceutical companies
\end{abstract}


of Pakistan and will test a proposed model, using bootstrapped moderated analysis. This research considers the resource-based view of the firm as well as the socio-materiality theory. Practical implications for top executives are also discussed. There is a need to convert big data into meaningful information for strategic decision making. Management accountant plays vital role with the help of new skills set to develop newer expertise and make a bridge between data analysts and business executives as a moderator. To this end, this research focuses on identifying the gaps in the existing literature as well as proposing the course of action which can be undertaken for empirical study.

\section{Introduction}

This study focuses on the specific problems and the practical as well as theoretical implication of this research so that the contribution of this study to the body of knowledge related to the field of Big Data Analytics' impact on organisation innovative performance via the moderating role of management accountant can be demonstrated. The previous work on Big Data Analytics has been developed upon by suggesting that actionable insight can be obtained through the analyses of large volumes of data, thus helping the businesses to transform themselves and so achieve competitive advantage (Chen et al., 2012). Due to the usage of big data analytics, the work of management accountant has been changing and it is likely the management accountant's role will be freed from the routine work. The usage of Al (Artificial Intelligence) and RPA (Robotics Process Automation) will take over the routine processing of everyday transactions and this will lead to management accountants time being freed to be much more increasingly utilised in performance of higher value adding activities. As the role of management accountant is knowing the management accounting concepts based on their importance in the business and also knowing which data is to be used so that the appropriate and relevant data can be obtained from the relevant department. Hence the role of the management accountant in the new age is one of a bridge between the data scientists and analysts and the businesses.

\section{Background of Big Data Analytics Capabilities, Innovative Performance and Strategic Role of Management Accountant}

Big data analytics capabilities (BDAC) are emerging as a hot topic among scholars and practitioners. BDAC is defined as a comprehensive approach to the management, processing and analysis of the $5 \mathrm{~V}$ data-related dimensions of volume, variety, velocity, veracity and value, to create applicable or practicable ideas for delivering sustained value, enabling performance measurement and achieving competitive advantages (Wamba et al., 2015).

A number of people associated with this field are of the view that BDAC is perhaps the "fourth paradigm of science"(Strawn, 2012), a "new paradigm of knowledge assets" (Hagstrom, 2012), or "the next frontier for innovation, competition, and productivity" (Manyika, 2011). The important thing to consider here is that these involve the combination of the usage of all of the different BDAC related tools, infrastructure and the related technologies which include the mobile devices, social media, cloud-based operations as well as the Internet of things to be able to achieve and then sustain their competitive advantage(s). For example, the use of BDAC does lead to improved decision making based on large data sets and innovative ways to learn, organize and innovate (Bean \& Kiron, 2013; Yiu, 2012) thus, improving the customer relationship management, reinforcing operations risk management, and enhancing and improving operational efficiency as well as the overall performance of the business organization (Bean \& Kiron, 2013). 
Some previous studies of the information systems (IS) investments driven business value have indicated mixed results, producing what is considered to be 'IT productive paradox'. Some experts have even supported the argument that it is not necessary that IS investments would lead to improved efficiency and effectiveness at the operational level (Roach, 1987; Solow, 1987; Strassmann, 1990).

Such studies suggest that such an absence of a positive relationship between IS investment and business performance found in previous studies may be the result of several factors such as the lack of appropriate data, the significant time lag between IS investments being made and the business value being generated from such investments, the lack of assessments related to the indirect benefits of IT, and the proper depth and breadth of analysis of ISrelated benefits (Anand et al., 2013; Brynjolfsson \& Hitt, 2000; Brynjolfsson \& Yang, 1996; Devaraj \& Kohli, 2003).

Big data analytics (BDAC) is an approach to analyse large and complex data sets and select hidden information that can help organizations carry out efficient decision making(Report, July 2014). The volume of Big Data has increased dramatically in previous years and is further expected to increase in the coming years due to the increased usage of innovative technologies (Ahmed \& Saeed, 2014).

In the meantime, while the organizations have focused mainly on the bottom line i.e. profit generation and enhancement of profitability, there is a considerable scope for improving the control over the big data itself. Variety, velocity, and veracity are the vital features of the BDAC. BDAC tools and techniques can be applied to the large amount of data available to analyse outcomes for improvement of the organization performance (Kaisler et al., 2013; Sagiroglu \& Sinanc, 2013).

Over the last few years, the exponential growth in the volume of data has resulted in Big Data being considered as the key source of competitive advantage. In many different fields such as information technology, telecommunication, theoretical computing, mathematics, data mining and data warehousing, Big Data is being used to analyse the consumers' behaviour patterns so as to identify and focus on their future consumer behaviour. Currently more than 3.2 billion people of the world's population are connected to internet. $46 \%$ of these are connected via the use of smart phones. With the shifting of the cellular technology from ordinary cell phones towards smart phones, the proportion of people, using internet is also increasing. It is forecasted that by 2020 around 7 billion people worldwide will be using internet out of which $52 \%$ will be using smart phones to access the internet. By 2050 these figures are likely to be $95 \%$ of world population. Every device which is connected to the internet results in generation of large volume of data which in turn requires sophisticated systems to store and analyse it.

Around 5 billion people over the globe call, text, tweet, send emails and browse on mobile devices (Russom, 2011). Similarly in 2012, 34\% of all emails were sent through smart phones (Radicati \& Hoang, 2012), and this number is also increasing rapidly with the growth of and usage of smart phones (Alam, 2011; Khan et al., 2014).

It is estimated that around $40 \%$ of the world's population has internet connection today. The number of internet users has increased considerably from 0.4 Billion in 2000 to 3.4 Billion in 2016 [19]. This increase has had its consequences in the form of increased total internet traffic. In 1992, internet transferred approximately $100 \mathrm{~GB}$ of data per day, whereas this figure shot up to 100 gigabytes per second (GBps) by 2002 . This has further crossed $20,000 \mathrm{GBps}$ (Index, 2016). 
Not just that but also the fact that mobile computing has affected the workplace dramatically and brought many benefits to internet users in the form of wireless connectivity, increased productivity and easy mobility. Google Consumer Barometer (Kariuki \& Kagiri) shows positive trends towards acceptance of mobile devices both in developed and developing countries. The sale of smart phones and tablets has already gone beyond the sales of Workstations and PCs. As per the Internet live statistics (Statistics, 2016) counter, over 1.6 Billion smart phones were sold in the first eight months of 2016 compared to only 142 Million computers.

Big Data has countless uses and many different organizations of all sizes are looking for ways to improve their performance by using big data analytics tools (Talia, 2013). Yin and Kaynak (2015) identified many challenges faced by different organizations when dealing with Big Data. One of the key challenges for the IT professionals and researcher is to deal with the programs and applications that continuously generate very large volume of data at very high speed. Enormous growth has been observed in the data production during the last two years, in fact, $90 \%$ of the world's current data has been generated in the last two years alone(Yin \& Kaynak, 2015). Massive amount of data is continuously generated and transferred through network by various internet entities, such as, video on demand, news streaming and ecommerce websites. Many websites are producing data at very high speed. For example, Twitter generates over 350,000 tweets per minute and over half a billion tweets per day on average (Mukherjee \& Shaw, 2016). In the same manner, Google processes around 40,000 search queries in every second on average (Statistics, 2016). Likewise, astronomy effort, such as Palomar Transient Factory in Southern California, is looking for new phenomena in the sky and roughly captures 30 terabytes of data every night (Statistics, 2016). Mobile devices produce huge quantity of data at enormously high speed. Cisco has developed different forecasting tools Riaz et al (2017), based on their Visual Networking Index(VNI), that predict that "Global mobile traffic will grow three times faster than Global fixed IP traffic from 2015 to 2020 ".

Furthermore, "Global mobile data traffic will grow 8-fold from 2015 to 2020, a compound annual growth rate of 53\%". This massive shift of IP traffic from fixed to wireless network will introduce number of challenges for Network architects. Telecom companies are sitting on a gold mine, as they have plenty of data. But what they require is a proper analysis of both structured and unstructured data to get deeper insights into customer behaviour, their service usage and interests real-time (Riaz et al., 2017). Since, half of the data is now being transferred via mobile and in 2012, according to study $90 \%$ of the data will be transferred through mobile and tablet devices (wireless connections). Now the technology is getting changed and majority of the data is being transferred on wireless connections (Van Den Dam, 2013). But just to sustain in the market, IT based industries need to reinforce their strategies based on the current scenario. They also have an opportunity to target this untapped market. The IT based industry has an advantage over other industries due to the maximum bandwidth and depth of data it collects in the course of normal business. For example, an operator serving 8 million prepaid mobile subscribers generates around 30 million Call Data Records daily, equalling 11 billion records annually. If the same operator also provides post-paid and fixed lines services, then there is even more volume and variety of data at the ready. Big Data helps customer care operators improve their marketing effectiveness. Relevant actions can be taken based on real-time information without the need to wait for data extraction or manual data mining. Big Data can help gather real-time customer satisfaction information through social media listening or Voice of the Customer analysis. It can also improve customer experience by identifying the most valuable customers who would benefit from dedicated 
treatment and better services (Van Den Dam, 2013). Cloud based services could help IT based industries to manage and secure customer's data. These industries can create new products just to utilize the big data with wireless connections. Top players like Google, Skype, and Netflix may be interested in behavioural data to target consumers with specific content.

Big data users proved to be the fundamental pillar in economic development of any region in the world because they have the knowledge, skills and ability to transform ideas to products (Duval-Couetil, Shartrand, \& Reed, 2016).They have to continuously improve their existing processes and products, and develop new products that match market requirements. Especially in situations where a technological discontinuity occurs, there is a need for speedy capability reconfiguration or substitution (Lavie, 2006). To be able to overcome external shocks, new capabilities are needed (Teece, 2007; Zollo \& Winter, 2002). The prevalence of Big Data and the usage of the same can result in enhancement in innovative performances, which then leads to further improvement in economic development. Innovation is increasingly becoming part of the core strategies of achieving and sustaining competitive advantage (Douglas, 2012). In other words, innovation, which can be termed as the implementation of creative ideas within the organisation, in a very efficient and effective manner, can and does, lead to businesses achieving and sustaining competitive advantages.

The usage of different technologies in the field of IT related to Big Data has resulted in radical changes being made to businesses as a whole. Many existing functions are being changed in terms of their requirements as well as their scope. The accounting and finance profession is no exception to it. Within this profession the scope and need of the management accountant is also going through radical changes. The ever-increasing usage of Big Data Analytics is creating a requirement for many organizations to increase their emphasis on enhancing the coordination and cohesion of their internal departments and functions, thereby improving their supply chain, ultimately leading to increased value creation within their supply chains as well as within the entire business. Artificial Intelligence, Internet of things, Big Data Analytics are creating what is being termed as Industry 4.0 in which digitization is used to create and enhance business value via e-commerce, digital marketing, customer experience etc. All these are being made possible due to massive amount of data being made available. However, it is not just the Big Data that is important. It is the ability to convert that Data into meaningful Information and then be able to use that Information to deliver what is needed in order to create and enhance business value. However, this is leading to newer opportunities for management accountants to learn new things and new skills and hence develop newer expertise. Even before the existence of Big Data, the crucial role of the management accountants had always been that of value creation which is primarily related to the formulation of strategy as well as the analysis, planning and execution of those strategies. Due to presence of much superior software, the decision-making processes will be greatly improved. With better decision making, and much better and detailed data analytics coming into play, the management accountant will be increasingly able to enhance organization wide value creation.

The prevalence of Big Data also leads to another position being created and that is of the Data Scientist. However, while the data scientist uses his relevant knowledge to search for and identify the relevant patterns in the existing pools of data, the role of management accountant is one of knowing the management accounting concepts related to their importance to the business and also knowing which data is to be used so that the appropriate and relevant data can be obtained from the relevant department. Hence the role of the 
management accountant in the new age is one of a bridge between the data scientists and analysts and the businesses. On their own, the data scientists have the ability to do their technical work but they lack the understanding of the relevant domain as well as knowing which questions to ask in which scenario(s). At the same time, the businesses on their own will not be able to fully understand the true potential of the data analytics. The management accountant acts as a bridge between these two. In this new age of big data the role of management accountant as a strategic business partner is possible when the management accountant learns and develops new skills like extraction relevant data for the relevant scenarios and relevant data and critical thinking with respect to the strategic issues. These are in addition to the existing skills.

\section{Literature Review Big Data Analytics}

Big Data Analytics develops on the previous work by suggesting that actionable insight can be obtained by analysing large volume of data, thereby helping the businesses to transform themselves and hence achieve competitive advantage (Chen et al., 2012). In spite of the large potential that Big Data Analytics carries with it, there is very little research that would indicate how the businesses need to structure themselves to gain the business value from the investments being made in the big data analytics area. There is also very little understanding regarding the different factors involved in generating such gains (Vidgen, Shaw \& Grant, 2017). A large number of reports related to big data analytics capability, coming from case studies, press or consultancy firms, are not built upon the theoretical insight needed for understanding the benefits of big data analytics capability and at the same time, do not focus on the empirical evidence obtained from large scale analyses (Gupta, 2016). Research conducted recently has indicated that there are a number of companies which are unable to create value from their investments made in big data analytics capability (Popovič, Hackney, Tassabehji, \& Castelli, 2018; Wamba et al., 2017). At the same time, there are some companies which suggest that big data will actually hurt them instead of benefitting them (Kiron, 2017). Consequently, how organizations should focus on big data analytics capability is not very well understood. Also there is insufficient empirical evidence regarding value creation from investments made in this field (Mikalef, Pappas, Krogstie, \& Giannakos, 2018). Although many studies have indicated that it is important to focus on all aspects surrounding big data (Constantiou \& Kallinikos, 2015; Sharma, Mithas \& Kankanhalli, 2014), there is a scarcity of empirical studies on this topic, particularly how to achieve the performance gains and which factors are important to obtain such gains (Vidgen et al., 2017). So, the important thing to consider here is: What big data analytics capability actually is? It is the combination of data, technology and human resources, both in the managerial positions and the technical staff, to be used in an effective manner so as to carefully develop the capabilities that are difficult to copy and transfer (Vidgen et al., 2017). Most of the studies done so far on area of big data analytics capability assume that organizations which develop these capabilities tend to focus on same approaches and hence they lack heterogeneity. At the same time, empirical studies are derived from the understanding that resources for building big data analytics capability are of equal importance, without considering different contexts(Gupta, 2016). It is increasingly important for different companies to understand the requirement for core big data analytics resources which create different values for them, particularly as they tend to increase their investments in this area (Abbasi et al., 2016).

A widely used definition of big data analytics regards them as " $a$ new generation of technologies and architectures, designed to economically extract value from very large 
volumes of a wide variety of data, by enabling high velocity capture, discovery and/or analysis" (Mikalef et al., 2018). The primary reason for being involved in Big data analytics is that it helps in better informed decision making (Abbasi et al., 2016). There are many research papers which show that use of big data analytics can generate considerable value when applied to problems in particular domains like supply chain management, marketing, health care etc. (Raghupathi \& Raghupathi, 2014; Waller \& Fawcett, 2013; Wang et al., 2016). Furthering this fact is the report delivered by MIT Sloan Management Review which showed that usage of big data analytics can lead to innovation and companies which lead in terms of their ability to adopt are much likely to innovate and bring newer products and services to markets compared to other companies which are slow to adopt the changes (Ransbotham \& Kiron, 2017).

A number of studies have identified separately, the factors which play a very important role in the integration of big data analytics within the organization. Gupta (2016) were able to measure an organisation's capability to integrate big data analytics and organization and be able to generate gains. This measure segregates tangible resources, intangible ones as well as human resources. In such cases, tangible resources generally include financial resources, physical infrastructure as well as organisational data. Human resources include technical as well as business analytics skill. The results of this approach indicated that carrying out investments in such organizational resources can result in increase in market share as well as organizational performances. In a similar manner, another study was able to show empirically, that overall organizational performance can be improved by investing in infrastructure, managerial capabilities as well as personnel technical expertise capabilities (Wamba et al., 2017). While research is showing increasingly the core areas which help in developing the big data analytics capabilities, yet the underlying assumption still remains that all organizations need to focus equally on all the elements (Mikalef \& Pateli, 2017). Resultantly there are very few suggested approaches via which organizations can gain value from their investments in big data capabilities and even less than that is the emphasis on the context within which such gains can be developed. One of the major problems related to the Big Data is the existence of the unstructured data, also known as the "human information". Financial records, weather records, scientific computation and simulation, geospatial images, videos and still images, as well the call centres data generated by different social media sites all fall under this category (Douglas, 2012). This unstructured data accounts for almost $80 \%$ of all of the Big Data (Holzinger et al., 2013).

In the researchers conducted previously in the broader area of Information Systems, there was a clear indication that the success of many IT related projects was based on the context in which they were carried out as well as other contingency factors (Bechor, Neumann, Zviran, \& Glezer, 2010). Petter, DeLone and McLean (2013) also indicated that contextually, different resources will have different impact (increased or decreased) in realization of performance related gains.

So, there is a limited research available related to big data analytics which shows the importance of different resources in different contexts and how the combination of the context and the resources can lead to improved performances.

Due to the shift in the way business is being conducted, there is an increasing need to change the way business analysis is being carried out. This is where the role of the management accountant is becoming more and more important. A variety of jobs in the management accountant's domain of working are changing. A recently conducted IMA Pulse survey carried 
out by ACCA (Association of Chartered Certified Accountants) and IMA (Institute of Management Accountants) has indicated that $42 \%$ of the Management accountants fear job loss while another research conducted by Forrester Research Inc. forecasted that $72 \%$ of the jobs in management, finance and business may be lost by 2020 .

Currently, as in the past, the role of the management accountant has been one of value creation. But the reality has been that the involvement of the management accountants in lower level activities including transaction processing, leads to the management accountant being unable to provide strategic insights to the senior management in the manner and to the extent required. With the usage of Big Data, the management accountant's role will be freed from the routine work. By 2020 an estimated 40\% of the transaction processing including management reporting, budgeting etc. is likely to be eliminated due to automation. The usage of Al (Artificial Intelligence) and RPA (Robotics Process Automation) which will be taking over the above-mentioned processing and management accountants work will lead to time being freed for the management accountant to be much more increasingly involved in performance of higher value adding activities.

\section{Big Data Analytics Capabilities and Innovative Performance with Strategic Role of Management Accountant}

Big data analytics is being considered by many as the next level of competition, innovation and productivity (Manyika, 2011). Consequently, both academics and practitioners have focused a lot of attention on how organizations can derive value from the use of big data analytics with the aim of attainment of organizational goals. A commonly used definition of big data analytics considers them as "a new generation of technologies and architectures, designed to economically extract value from very large volumes of a wide variety of data, by enabling high velocity capture, discovery and/or analysis" (Mikalef et al., 2017). The literature provides suggestions that big data analytics, when deployed in a focused and effective manner can help the firms to identify emerging opportunities and threats, generate critically important insight, and help them to adapt their ongoing operations to meet the requirements based on the trends identified in the competitive environment (Chen et al., 2012). Resultantly, the main competitive differentiator provided by big data analytics is the fact that organization wise decision-making becomes better informed (Abbasi et al., 2016). The increasing interest in big data analytics is clearly evident in companies which are operating in complex and fastpaced environments (Wang et al., 2016). These days managerial decisions are being increasingly based on real-time insight generated from big data, and the managers are focusing on taking a number of initiatives in this regard (Constantiou \& Kallinikos, 2015). Several research papers have indicated that by applying big data analytics to problems of specific domains (e.g. service provision, healthcare, supply chain management, marketing etc.) substantial value can be obtained (Raghupathi \& Raghupathi, 2014; Waller \& Fawcett, 2013; Wang et al., 2016). Further to these studies, a report by the MIT Sloan Management Review has shown that big data analytics can also become a source of innovation. Companies that are leaders in adoption of big data analytics are more likely to deliver new products and services when compared to the laggards (Ransbotham \& Kiron, 2017).

On the whole, in spite of the many claims that big data analytics helps in creating business value, there is still limited knowledge on the important organizational aspects and challenges when attempting to do so (Gupta, 2016; Wamba et al., 2017). Sharma et al (2014) highlight that although there is reasonable amount of evidence suggesting that big data analytics can help to create business value, a deeper analysis is still needed to prove the thesis that big data 
analytics does in fact lead to business value. New studies are arguing that obtaining value from big data analytics can be done as a result of focusing organizational diffusion of technologies and the organizational operations, and so there is a need to develop an organisation-wide big data analytics capability (Gupta, 2016). Building on these new studies and synthesizing definitions, Mikalef and Pateli (2017) have mentioned that big data analytics capability is the ability of a firm to deploy technology and talent in an effective manner so as to capture, store and analyze data, so that organization can obtain insight. In an empirical study, Vidgen et al (2017) have identified that organizations face different challenges in attempting to create value from big data analytics, and that these challenges have to do with how big data analytics are organized and used for maximum benefit. Several business reports are pointing to the same underlying issue in relation to the big data analytics with most challenges faced by companies in deriving business value being of an organizational nature (Kiron, 2017). Although this issue is increasingly becoming apparent in academic literature and practice, still there is limited understanding on what are the important organizational aspects when attempting to gain business value from big data analytics investments (Abbasi et al., 2016). Even more so, there is limited understanding on the influence which context has on developing such capabilities and shaping the factors which are important in realizing the performance gains (Günther et al., 2017).

Nonetheless, within the context of big data analytics some limited research is available which indicate that the importance of resources may, and usually does, differ based on the context within which it is examined, and that the combination of resources and context can lead to improvements of performance. While research to date has started to explain the role those different elements have, within such categories on the realization of performance related gains from big data analytics investments, there are still very few studies which examine the confluence of context related factors (Mikalef \& Pateli, 2017). At the same time, a large proportion of the studies conducted thus far have assumed that all the organizations face the same challenges, and hence they need to focus their investments in a uniform set of aspects. Secondly, although there are lots claims related to the enabling impact which big data analytics have on strengthening the existing or realizing performance gains, there is very limited empirical evidence to consolidate the claims. The findings so far reveal that deployment of different combinations of big data-related resources can lead to greater or lesser impact, and this is due to the effect of the context within which they are used. Specifically, it is revealing that if the environments are moderately uncertain, the performance gains are greatly influenced by the more technological and technical resources while within the highly uncertain conditions the organizational aspects and managerial skills are of greater importance. As a matter of fact, a number of business reports show the importance which organizational aspects can have in the realization of business value (Kiron, 2017), but there is very little empirical evidence which could lead to the above mentioned claims being confirmed. Such evidence also reveals the different combinations of factors which lead to performance gains. Some of findings have revealed that big data analytics must not be considered as solely a technical challenge. Rather it must be considered as an organizational one which requires combining it with the firm's business strategy. Therefore, it is critically important to understand the constituent components which enable such a combination between big data analytics as well as the business strategy, and which consequently lead to performance gains.

The results of these studies have a number of implications for practitioners. Firstly, these show that big data analytics is not just investing in technology, collecting large amounts of 
data, and letting the IT department to experiment, using such data, with novel analytics techniques.

Similarly, managers may consider the fine structure of microstructure planning, investment, coordination and control. This helps to ensure big data analytics capabilities management, which is one of the main pillars of BDAC. Finally, the most important pillar of big data analytics capabilities is big data analytics personnel skills capability. To strengthen this aspect of big data analytics capabilities, an organized effort needs to be made to develop technical knowhow, technological managerial know how, business know how and related know how for big data analytics. It has been identified that the idea of recommending that organizations accept the three-pillar strategy of big data analytics capabilities does sound highly theoretical. However, this conclusion is based on the findings from the data. This study is an early attempt to understand the big data phenomenon from the theoretical point of view of RBT, which is a well-established strategic theory of the firm. Although the practitioners of the big data have made excellent contribution to the existing literature of the big data domain, a considerable number of them have considered big data analytics literature almost exclusively as a technical capability (ot President, 2014). This shortcoming has been addressed in the existing literature by highlighting the vitality of several nontechnical resources, in addition to other resources such as data and technology, which are required to create a big data analytics capability. Some studies have made a very important contribution to the big data literature by presenting a theoretical framework of big data analytics capabilities which consists of several technical and nontechnical resources classified into three categories, while at the same time providing empirical evidence to provide support to the suggested theoretical framework. Using a survey data from 108 executive-level technology leaders, the relevant study provided empirical evidence of the relationship between big data analytics capability and firm performance and hence has validated that relationship. However, it is important to note that as discussed in this study, creating a big data analytics capability is quite a complex process because there is a requirement to have many organization wide tangible, human skills, and intangible resources. Another important consideration arising from this study is that it leads to the development of a theoretically based construct of the big data analytics capability while at the same time developing a psychometrically sound survey instrument to measure a firm's big data analytics capability. These big data analytics construct and its related measures have helped interested researchers to study the big data phenomenon so as to further the emerging enhance the research related to big data. This study also implies that in theory the construct related to big data analytics capability differs from digital capabilities such as IT capability. In other words, IT capabilities, besides other organization wide resources, include technologies related to information, communication, and connectivity (Bharadwaj et al., 2013). Also, IT capability supports the "day-to-day running of the firm" (Bharadwaj, $2000 \mathrm{p}$. 175). At the same time, big data related technologies help the organizations to extract insights from data which originate from multiple sources and be able to make decisions based on newly gleaned information. This study has provided quite some important insights for practice. This study has tried to highlight to the managers related to big data that in order to gain competitive advantage from the usage of big data, it is not only related to investing, collecting immense volumes of data, and being able to gain access to advanced and sophisticated technology but also relates to having big data-related technical, technological and management skills, pervasive organizational learning, and an organization wide culture which encourages obtaining insights extracted from data and places a lot of value on such activities. It is the combination of all these resources that helps to create an organisation- 
specific big data capability. Quite recently, some have started to address these issues by pointing out that big data analytics capability is not about data or technological advances (Marr, 2015; Ross, Beath \& Quaadgras, 2013).The first step in developing an organization wide capability is related to doing a self-assessment of the organization's strengths and weaknesses (Bharadwaj, 2000). As an example, scales relating to human skills can, and do, enable organizations to identify the requirement of the big data-related management and technical skills and compare them with the pool of such resources which the organisations already have. Without any doubt, an organisation's workforce is the most valuable asset it can have; however, hiring a wrong person in any job can be a recipe for disaster for organizations. As per some estimates, a wrongly hired employee can cost an organization as much as six times of the base salary of such an employee during the period of mis-hire (Smart, 2005). As the big data analytics courses are still in their very early stage (Chen et al., 2012), it is extremely important for organizations to assess their big data analytics related human skills because in the short term big data-specific human skills are likely to be heterogeneous across most organisations.

In recent times there have been rapidly occurring changes in the business world with the business environment becoming increasingly global, competitive and turbulent. This has led to a significant impact on the way people conduct their businesses whether it is manufacturing or non-manufacturing, big size, medium size or small sized company, a profit oriented one or a non-profit oriented one. Consequently, such rapid changes require every organization to continuously ensure a sustainable performance level in the global market.

\section{Discussion}

Conceptually speaking, big data relates to massive volume, velocity and variety of data items. The most important and challenging aspect of big data is not related to the storage capacity of such large volume and variety of data but to analyze such unstructured data in ways so as to be able to be able to convert it into meaningful information upon which action could be taken for the benefit of the organization. According to (Hilbert \& López, 2011) big data is capable of delivering important prospects to guide better decisions. Volume, variety, velocity and value are the defining characteristics of big data according to (C. P. Chen \& Zhang, 2014). Increasing usage of advanced IT devices like tabs, smart phones and laptops as well as usage of internet on such devices for social media services and corporate information systems has resulted in very large amounts of structured and unstructured data being continuously produced. This has resulted in businesses increasingly facing challenges in managing such data and information and building upon it for their advantage. Big data analytics can also be defined as the technologies and techniques that a company can deploy in order to analyze, on a very large scale, increasingly complex data for various applications with the intention to enhance the performance of the firm in many different areas. The technologies include tools related to usage of database and data mining while the techniques involve different analytical methods, suited to the requirement.

A study carried out by (Chen \& Zhang, 2014) has shown that big data analytics include such tools and techniques as high-tech data storage, management, analysis capability and visual technologies.

For the purpose of this study, the definition of BDA as given by (Srinivasan \& Swink, 2018), p. 3 ) has been used: "an organizational facility with tools, techniques, and processes that enable a firm to process, organize, visualize, and analyze data, thereby producing insights that enable data-driven operational planning, decision making, and execution". 
Numerous changes have occurred over the last 30 years in the way the management accountant's role is carried out, from bean counters to strategic business partners (Baldvinsdottir et al., 2009; Malmi et al., 2001). Historically as well as currently, the primary focus of management accountants has always been to improve the organizational performance and profitability. Traditionally, the management accountant's role has been mainly one of organizational cost keeping and budgeting and on carrying out process costing and budgets preparation and conducting variance analyses (Mishra \& Kanti, 2011). According to Tarigan and Kunto (2008) management accountant is trained to perform duties and functions that would meet the information requirements of top level management and to play its role in motivating to achieve organization's objectives. As per the work of Kaplan (1998) management accountants are no longer only the scorekeepers of past performance but become should be considered as the value adding members of managerial teams. The management accountant must be an important and highly skilled member of managerial team (Cooper, 1996). Management accountants of today are transforming from being mere bean counters to more important positions of financial and strategic managers. Tarigan and Kunto (2008) have stated that there are four categories of management accountant's role within an organization. It can be as an administrator or as a doer of work, or as a conceptor and finally as an actor. A management accountant plays the role of an administrator if he or she is involved in the administrative or bookkeeping related tasks, for example recording transaction or being a cashier. Management accountant would be playing the role of a doer if he or she were to be involved in running the accounting system related to the day-to-day operational activities. A management accountant can be considered to be carrying out the role of a conceptor if he or she has higher understanding level of various accounting concepts but those concepts are not considered important in the organization mainly because they have not come into use yet. Finally, Tarigan and Kunto (2008) have stated that a management accountant can also be a player if he or she is involved at the strategic level planning or providing information to top-level managers who are involved in the strategic planning and decision making.

Baldvinsdottir et al (2009) described the role of a management accountant in an organization management accountant felt differ to the non-financial managers because other managers did not fully understand and how to use the financial information.

This suggests the important role of management accountants in helping to provide information

for strategic decision-making and strategic control (Bromwich, 1996). The increasing globalization of business over the last two decades and the speed with which technological changes are coming about have also greatly impacted the role of management accountants (Burns \& Baldvinsdottir, 2007).

Strategic decision-making process involves "the scanning of the environment to gather data and making sense of it by developing cognitive models and building mental representations that guide managers' thinking and the direction of their decisions"(Bonn \& Fisher, 2011) p.7. With their expertise and experience, it is essential that the management accountants are involved in the strategic decision-making process and hence enhance the firm's effectiveness as a business entity.

\section{Conclusion}

This study focuses on the role big data analytics is playing in organizational innovative performance. This is affected by the influence of the role of management accountant. The 
emergence of the big data is affecting the way organizations are conducting their operations and to an extent their business strategies. Big data refers to the ever-increasing volume, variety and velocity of data which is emerging due to the increasing usage of internet through the cell devices as well as laptop and other computer systems. Over the last few years the amount of big data has been increasing at a much greater rate than before and this is giving rise to considerable opportunities for businesses to invest in the big data analytics capabilities and thus gain competitive advantage. However, the issue is that simply investing in the big data analytics capabilities is not enough. There is always the possibility that the investment may not be done properly and may ignore some of the factors which are important for the organization. In most cases the it is assumed that the investments needed in the technical personnel, the infrastructure as well as the managerial aspect of the big data analytics capabilities are more or less of equal importance. However, what is relevant is that the contextual importance also needs to be considered. When the contextual importance is considered then the relevant factors are given their due importance and hence big data analytics capabilities are developed and implemented in such a manner that help the organization to develop their innovative performance and hence are able to attain sustainable competitive advantage. The role of data scientist is very important in the analysis of the big data streams so that underlying trends can be obtained. However, if the analysis is left only to the data scientist, they will be able to conduct the data analysis without considering the business and accounting and financial aspects associated with that data. Similarly, business on their own will not be able to fully utilize the technical skills of the data scientists to maximize the benefits to be obtained. Hence the role of management accountant is very important to bridge the gap bet the data scientists as well as the businesses. The management accountants can use their business and accounting and financial knowledge to bring about the technical as well as managerial skills and utilize the big data analytics capabilities to the fullest and thus help the organization to attain sustainable competitive advantage by using the data insights obtained from the big data.

\section{References}

Abbasi, A., Sarker, S., \& Chiang, R. H. (2016). Big data research in information systems: Toward an inclusive research agenda. Journal of the Association for Information Systems, 17(2), I.

Ahmed, E. S. A., \& Saeed, R. A. (2014). A survey of big data cloud computing security. International Journal of Computer Science and Software Engineering (IJCSSE), 3(1), 7885.

Alam, M. M. (2011). Error corrected location determination in an outdoor wireless environment by using estimation, filtering, prediction and fusion techniques: A wifi application by using terrain based knowledge.

Anand, A., Wamba, F. S., \& Sharma, R. (2013). The effects of firm IT capabilities on firm performance: the mediating effects of process improvement.

Baldvinsdottir, G., Burns, J., Nørreklit, H., \& Scapens, R. W. (2009). The management accountant's role: conclusions. Financial management, 33-34.

Bean, R., \& Kiron, D. (2013). Organizational alignment is key to big data success. MIT sloan management review, 54(3), 1-6.

Bechor, T., Neumann, S., Zviran, M., \& Glezer, C. (2010). A contingency model for estimating success of strategic information systems planning. Information \& Management, 47(1), 17-29. 
Bharadwaj, A., El Sawy, O. A., Pavlou, P. A., \& Venkatraman, N. (2013). Digital business strategy: toward a next generation of insights. MIS quarterly, 471-482.

Bharadwaj, A. S. (2000). A resource-based perspective on information technology capability and firm performance: an empirical investigation. MIS quarterly, 169-196.

Bonn, I., \& Fisher, J. (2011). Sustainability: the missing ingredient in strategy. Journal of business strategy.

Bromwich, M. (1996). Strategic management accounting in management accounting handbook. The Chartered Institute of Management Accountants, 203-227.

Brynjolfsson, E., \& Hitt, L. M. (2000). Beyond computation: Information technology, organizational transformation and business performance. Journal of Economic perspectives, 14(4), 23-48.

Brynjolfsson, E., \& Yang, S. (1996). Information technology and productivity: a review of the literature. In Advances in computers (Vol. 43, pp. 179-214): Elsevier.

Burns, J., \& Baldvinsdottir, G. (2007). The changing role of management accountants. Issues in management accounting, 3, 117-132.

Chen, C. P., \& Zhang, C.-Y. (2014). Data-intensive applications, challenges, techniques and technologies: A survey on Big Data. Information sciences, 275, 314-347.

Chen, H., Chiang, R. H., \& Storey, V. C. (2012). Business intelligence and analytics: From big data to big impact. MIS quarterly, 36(4).

Constantiou, I. D., \& Kallinikos, J. (2015). New games, new rules: big data and the changing context of strategy. Journal of Information Technology, 30(1), 44-57.

Cooper, R. (1996). The changing practice of management accounting. MANAGEMENT ACCOUNTING-LONDON-, 74, 26-35.

Devaraj, S., \& Kohli, R. (2003). Performance impacts of information technology: Is actual usage the missing link? Management science, 49(3), 273-289.

Douglas, K. (2012). Infographic: big data brings marketing big numbers. In.

Duval-Couetil, N., Shartrand, A., \& Reed, T. (2016). The Role of Entrepreneurship Program Models and Experiential Activities on Engineering Student Outcomes. Advances in Engineering Education, 5(1), n1.

Günther, W. A., Mehrizi, M. H. R., Huysman, M., \& Feldberg, F. (2017). Debating big data: A literature review on realizing value from big data. The Journal of Strategic Information Systems, 26(3), 191-209.

Gupta. (2016). Toward the development of a big data analytics capability. Information \& Management, 53(8), 1049-1064.

Hagstrom, M. (2012). High-performance analytics fuels innovation and inclusive growth: use big data, hyperconnectivity and speed to intelligence to get true value in the digital economy. Journal of Advanced Analytics, 2, 3-4.

Hilbert, M., \& López, P. (2011). The world's technological capacity to store, communicate, and compute information. science, 332(6025), 60-65.

Holzinger, A., Stocker, C., Ofner, B., Prohaska, G., Brabenetz, A., \& Hofmann-Wellenhof, R. (2013). Combining $\mathrm{HCl}$, natural language processing, and knowledge discovery-potential of IBM content analytics as an assistive technology in the biomedical field. Paper presented at the International Workshop on Human-Computer Interaction and Knowledge Discovery in Complex, Unstructured, Big Data.

Index, C. V. N. (2016). The Zettabyte Era-Trends and Analysis, Cisco. Cisco company, June. 
Kaisler, S., Armour, F., Espinosa, J. A., \& Money, W. (2013). Big data: Issues and challenges moving forward. Paper presented at the 2013 46th Hawaii International Conference on System Sciences.

Kaplan, R. S. (1998). Innovation action research: creating new management theory and practice. Journal of management accounting research, 10, 89.

Khan, N., Yaqoob, I., Hashem, I. A. T., Inayat, Z., Ali, M., Kamaleldin, W., . . Gani, A. (2014). Big data: survey, technologies, opportunities, and challenges. The Scientific World Journal, 2014.

Kiron, D. (2017). Lessons from becoming a data-driven organization. MIT sloan management review, 58(2).

Lavie, D. (2006). Capability reconfiguration: An analysis of incumbent responses to technological change. Academy of Management Review, 31(1), 153-174.

Malmi, T., Seppala, T., \& Rantanen, M. (2001). The practice of management accounting in Finland-a change? Liiketaloudellinen aikakauskirja, 480-501.

Manyika, J. (2011). Big data: The next frontier for innovation, competition, and productivity. http://www. mckinsey.

com/Insights/MGl/Research/Technology_and_Innovation/Big_data_The_next_frontier for_innovation.

Marr, B. (2015). Big Data: Using SMART big data, analytics and metrics to make better decisions and improve performance: John Wiley \& Sons.

Mikalef, P., Framnes, V. A., Danielsen, F., Krogstie, J., \& Olsen, D. (2017). Big Data Analytics Capability: Antecedents and Business Value. Paper presented at the PACIS.

Mikalef, P., Pappas, I. O., Krogstie, J., \& Giannakos, M. (2018). Big data analytics capabilities: a systematic literature review and research agenda. Information Systems and e-Business Management, 16(3), 547-578.

Mikalef, P., \& Pateli, A. (2017). Information technology-enabled dynamic capabilities and their indirect effect on competitive performance: Findings from PLS-SEM and fsQCA. Journal of Business Research, 70, 1-16.

Mishra, D., \& Kanti, S. (2011). Management Accountant: Role \& future challenges. Management Accountant: Role \& Future Challenges (March 16, 2011).

Mukherjee, S., \& Shaw, R. (2016). Big data-concepts, applications, challenges and future scope. International Journal of Advanced Research in Computer and Communication Engineering, 5(2), 66-74.

Petter, S., DeLone, W., \& McLean, E. R. (2013). Information systems success: The quest for the independent variables. Journal of management information systems, 29(4), 7-62.

Popovič, A., Hackney, R., Tassabehji, R., \& Castelli, M. (2018). The impact of big data analytics on firms' high value business performance. Information Systems Frontiers, 20(2), 209222.

Radicati, S., \& Hoang, Q. (2012). Email statistics report, 2012-2016. The Radicati Group. Inc., London.

Raghupathi, W., \& Raghupathi, V. (2014). Big data analytics in healthcare: promise and potential. Health information science and systems, 2(1), 3.

Ransbotham, S., \& Kiron, D. (2017). Analytics as a source of business innovation. MIT sloan management review, 58(3).

Report, A. (2014). Retrieved from Big data analytic is just not a passing trend. http://www.analysysmason.com/Research/Content/Reports/Big-dataanalytics-

Jul2014/ (last visited: September 16th, 2016) 
Riaz, F., Alam, M., \& Ali, A. (2017). Filtering the big data based on volume, variety and velocity by using Kalman filter recursive approach. Paper presented at the 2017 IEEE 3rd International Conference on Engineering Technologies and Social Sciences (ICETSS).

Roach, S. S. (1987). America's technology dilemma: A profile of the information economy: Morgan Stanley.

Ross, J. W., Beath, C. M., \& Quaadgras, A. (2013). You may not need big data after all. Harvard Business Review, 91(12), 90-+.

Russom, P. (2011). Big data analytics. TDWI best practices report, fourth quarter, 19(4), 1-34.

Sagiroglu, S., \& Sinanc, D. (2013). Big data: A review. Paper presented at the 2013 International Conference on Collaboration Technologies and Systems (CTS).

Sharma, R., Mithas, S., \& Kankanhalli, A. (2014). Transforming decision-making processes: a research agenda for understanding the impact of business analytics on organisations. In: Taylor \& Francis.

Smart, B. D. (2005). Topgrading: How leading companies win by hiring, coaching, and keeping the best people: Penguin.

Solow, R. M. (1987). We'd better watch out. New York Times Book Review, 36.

Srinivasan, R., \& Swink, M. (2018). An investigation of visibility and flexibility as complements to supply chain analytics: An organizational information processing theory perspective. Production and Operations Management, 27(10), 1849-1867.

Statistics, T. U. (2016). Internetlivestats. com http://www. internetlivestats. com/twitterstatistics. In: Accessed.

Strassmann, P. A. (1990). The business value of computers: an executive's guide: Information Economics Press.

Strawn, G. O. (2012). Scientific Research: How Many Paradigms? Educause Review, 47(3), 26. Talia, D. (2013). Clouds for scalable big data analytics. Computer(5), 98-101.

Tarigan, J., \& Kunto, Y. S. (2008). Application of Accounting Concepts in the Workplace: A Research of Management Accountant in Surabaya, Indonesia. Journal of International Business Research, 7, 89.

Teece, D. J. (2007). Explicating dynamic capabilities: the nature and microfoundations of (sustainable) enterprise performance. Strategic management journal, 28(13), 13191350.

Van Den Dam, R. (2013). Big data a sure thing for telecommunications: Telecom's future in big data. Paper presented at the 2013 International Conference on Cyber-Enabled Distributed Computing and Knowledge Discovery.

Vidgen, R., Shaw, S., \& Grant, D. B. (2017). Management challenges in creating value from business analytics. European Journal of Operational Research, 261(2), 626-639.

Waller, M. A., \& Fawcett, S. E. (2013). Data science, predictive analytics, and big data: a revolution that will transform supply chain design and management. Journal of Business logistics, 34(2), 77-84.

Wamba, S. F., Akter, S., Edwards, A., Chopin, G., \& Gnanzou, D. (2015). How 'big data'can make big impact: Findings from a systematic review and a longitudinal case study. International Journal of Production Economics, 165, 234-246.

Wamba, S. F., Gunasekaran, A., Akter, S., Ren, S. J.-f., Dubey, R., \& Childe, S. J. (2017). Big data analytics and firm performance: Effects of dynamic capabilities. Journal of Business Research, 70, 356-365. 
Wang, G., Gunasekaran, A., Ngai, E. W., \& Papadopoulos, T. (2016). Big data analytics in logistics and supply chain management: Certain investigations for research and applications. International Journal of Production Economics, 176, 98-110.

Yin, S., \& Kaynak, O. (2015). Big data for modern industry: challenges and trends [point of view]. Proceedings of the IEEE, 103(2), 143-146.

Yiu, C. (2012). The big data opportunity. Policy exchange, 8, 813.

Zollo, M., \& Winter, S. G. (2002). Deliberate learning and the evolution of dynamic capabilities. Organization Science, 13(3), 339-351. 